\begin{tabular}{c} 
Brazilian Journal \\
of Chemical \\
Engineering \\
\hline
\end{tabular}

ISSN 0104-6632

\title{
LEACHING OF MALACHITE ORE IN AMMONIUM SULFATE SOLUTIONS AND PRODUCTION OF COPPER OXIDE
}

\author{
A. Ekmekyapar ${ }^{1}$, N. Demirkıran ${ }^{1 *}$, A. Künkül ${ }^{1}$ and E. Aktaş ${ }^{2}$ \\ ${ }^{1}$ Department of Chemical Engineering, Faculty of Engineering, Inonu University, Malatya, 44280, Turkey. \\ Phone: +904223774760 \\ E-mail: nizamettin.demirkiran@inonu.edu.tr \\ ${ }^{2}$ Malatya Sugar Factory, Malatya, 44080, Turkey. \\ (Submitted: January 11, 2014 ; Revised: April 4, 2014 ; Accepted: April 4, 2014)
}

\begin{abstract}
Malachite ore is one of the most important of oxidized copper ores. Copper production can be performed by using this ore. In this work, the leaching kinetics of malachite in ammonium sulfate solutions was investigated, and metallic copper was recovered by a cementation method from the resulting actual leach solution. Copper (II) oxide was prepared by an isothermal oxidation method from the cement copper. In the leaching experiments, the effects of reaction temperature, particle size, and stirring speed on copper leaching from malachite ore were studied. In the cementation experiments, metallic zinc was used as the reductant metal to recover the copper from the solution. Thermal oxidation of cement copper was performed under isothermal conditions. It was found that the leaching rate increased with increasing stirring speed and temperature, and decreased with particle size. It was observed that the leaching reaction fit to diffusion through the product layer. The activation energy of the leaching process was determined to be $25.4 \mathrm{~kJ} / \mathrm{mol}$. It was determined that the copper content of the metallic product obtained by the cementation method increased up to $96 \%$. It was found that copper oxide prepared from cement copper had a tenorite structure.

Keywords: Copper; Malachite ore; Leaching; Cementation; Thermal oxidation.
\end{abstract}

\section{INTRODUCTION}

Metal production from any metal source, like ore, concentrate, and secondary sources (various industrial wastes containing metals and scrap metals, etc.) is performed by one of the pyrometallurgical and hydrometallurgical methods, or by a combination of them. The hydrometallurgical method contains leaching, separation and purification, and recovery steps. In the leaching step, the metal source is leached by using a suitable lixiviant. After this step, the resulting leach solution is purified to remove the unwanted impurities by means of various methods, such as precipitation, adsorption, ion-exchange, solvent extraction, electrolysis, and cementation. Finally, the metal value is obtained in the form of metal or a suitable metal compound by applying recovery processes (Venkatachalam, 1998; Han, 2002).

Among the non-ferrous metals, copper is one of the most important metals used in industry because of its electrical, thermal, optical and catalytic properties. Copper is mainly used in the electrical and electronics industries due to its high electrical conductivity. It is generally found in nature in the form of sulfide and oxide minerals, such as azurite, malachite, tenorite, chrysocolla, bornite, brochantite, enargite, chalcopyrite, chalcocite, or covellite (Arzutuğ et al., 2004; Naguman, 2008; Salavati-Niasari and Davar, 2009; Tsogtkhankhai et al., 2011).

Malachite, which is an oxidized copper ore, can be used to produce copper. Because malachite ores are generally low-grade, hydrometallurgical methods

*To whom correspondence should be addressed 
are often applied to obtain copper from them. Sulfuric acid is generally used as leach reagent to extract the copper from the ore. However, malachite ores often contain high levels of contaminants depending on the ore source, such as $\mathrm{Fe}, \mathrm{Zn}, \mathrm{Al}, \mathrm{Pb}$, silica, and various clay minerals. Therefore, when sulfuric acid is employed as lixiviant to extract copper from the ore, other metals in the ore matrix are also dissolved together with the copper during the leaching process. These contaminants that pass into the solution must be removed prior to the electro-winning step of copper to increase both the quality of the final product and the current efficiency of the process. In addition, the gangue minerals existent in the ore matrix can cause high consumption of acid. For these reasons, the use of weakly acidic or basic lixiviants can be more favorable in the leaching step of the hydrometallurgical processing of malachite ore (Oudenne and Olson, 1983; Awakura et al., 1991; Ekmekyapar et al., 2003; Bingöl et al., 2005).

Ammonia and its ammonium salts have a weakly basic and a slightly acidic character; therefore, they can be used as lixiviant for the leaching of ores containing gangue minerals. Ammonia-containing solutions can be attractive solvents in hydrometallurgy due to the advantages such as low cost, low toxicity, low corrosive effect, and ease of regeneration of ammonia by evaporation (Ghosh et al., 2002; Wang et al., 2009).

Ammonia-containing solutions are primarily employed for the extraction of non-ferrous metals from various sources. The oxide and carbonate ores of copper, such as tenorite $(\mathrm{CuO})$, malachite $\left(\mathrm{CuCO}_{3} \mathrm{Cu}(\mathrm{OH})_{2}\right)$, and azurite $\left(2 \mathrm{CuCO}_{3} \mathrm{Cu}(\mathrm{OH})_{2}\right)$ are readily soluble in ammonia-containing solutions. In ammonia leaching of oxidized copper ores, as the dissolution reactions happen at mildly acidic or basic conditions, some metal impurities, which pass into the solution during the dissolution of ore, precipitate because of the high $\mathrm{pH}$ of the solution. Besides, ammonia forms stable complexes with copper ions, and this can lead to an increase in the dissolution rate of copper from ore. Thus, ammonia allows for selective extraction of the copper from ore, leaving the undesired components in the residue (Blanco et al., 1999; Arzutuğ et al., 2004; Ekmekyapar et al., 2003; Wang et al., 2009).

Hence, it can be said that the use of ammoniacal solutions in the leaching step may reduce the number of separation processes to be applied to the resulting leach solution, and this may improve the economy of the process. Because ammoniacal leaching reagents especially ensure precipitation of iron in the form of hydroxide, they may offer a cleaner solution for the metal recovery step. However, if necessary, the above-mentioned additional separation processes can be applied to remove the other impurities from the leach solution. Eventually, a high purity solution can be obtained for electrolytic recovery of copper.

Various ammoniacal solutions have been used as lixiviant in the leaching of malachite ore provided from different locations (Oudenne and Olson, 1983; Künkül et al., 1994; Ekmekyapar et al., 2003; Bingöl et al., 2005; Wang et al., 2009; Lui et al., 2010; Liu et al., 2012; Ekmekyapar et al., 2012a; Künkül et al., 2013). After leaching of the malachite ore, the dissolved copper in the purified leach solution can be recovered in the form of metallic copper by cementation, direct electrowinning, or solvent extractionelectro-winning methods. In the solvent extraction method, copper in the leach solution is first taken up in the organic phase by using copper-selective extractants in the extraction step of the process. Afterwards, the organic phase loaded with copper is subjected to the stripping operation with a strong acid, and copper is transferred from the organic phase to the aqueous phase. Thus, an extremely pure solution is obtained for recovery of copper by electrolysis (Venkatachalam, 1998; Agarwal et al., 2010). Copper recovery from various solutions containing copper ions has been investigated by using different extractants by means of the solvent extraction technique (Fouad, 2009; Hu et al., 2010; Deep et al., 2010; Staszak et al., 2012). Although solutions having high-purity are obtained by this method, the cost of the extractants used is one of the disadvantages of this process.

Among the metal gaining processes from the solution, a metal displacement reaction or cementation method is one of the most effective and economic methods applied successfully for attaining valuable metals from industrial solutions (Gupta and Murkherjee, 1990; Venkatachalam, 1998; Noubactep, 2010; Demirkıran, 2013a). In this method, the copper dissolved in the solution is reduced to the metallic state by a more active metal, such as iron, aluminum, or zinc. However, metallic copper obtained by the cementation method is not of high-purity because cement copper tends to form the oxide during the drying procedure (Habashi, 1997; Karavasteva, 2005; Demirkıran et al., 2007). The cement copper can be marketed as a commercial powder product, or it can be purified by applying pyrometallurgical refining or electro-refining processes (Gana et al., 1995; Figueroa et al., 1997). Besides, high-purity metallic copper can be produced by electrolysis after the cement copper is dissolved in sulfuric acid solution. Furthermore, different copper compounds can be prepared by means 
of various methods, such as precipitation, crystallization, and evaporation. Gaining of copper from various synthetic pure solutions or actual leach solutions containing copper ions by the cementation reaction has been studied by using iron, aluminum, and zinc as the reductant metal (Djokic, 1996; Dib and Makhloufi, 2004; Karavasteva, 2005; Demirkıran et al., 2007; Ahmed et al., 2011; Demirkıran and Künkül, 2011; Ekmekyapar et al., 2012b; Demirkıran, 2013b).

In this work, the leaching kinetics of malachite in ammonium sulfate solutions was investigated, and metallic copper was recovered by the cementation method from the resulting actual leach solution. Copper (II) oxide was prepared by an isothermal oxidation method from the cement copper. In the leaching experiments, the effects of reaction temperature, particle size, and stirring speed on copper leaching from malachite ore were studied. In the cementation experiment, metallic zinc was used as the reductant metal to recover the copper from the solution. Due to the above-mentioned advantages of ammoniacal solutions, ammonium sulfate was chosen as solvent in this study. In addition, the solution containing sulfate is more suitable for electrolytic recovery of copper from the solution.

During the leaching step of this study, the overall reaction occurring between malachite and ammonium sulfate can be written as follows:

$$
\begin{aligned}
& \mathrm{CuCO}_{3} \mathrm{Cu}(\mathrm{OH})_{2}+2\left(\mathrm{NH}_{4}\right)_{2} \mathrm{SO}_{4} \rightarrow \\
& 2 \mathrm{Cu}^{2+}+4 \mathrm{NH}_{3}+2 \mathrm{SO}_{4}{ }^{2-}+\mathrm{CO}_{2}+3 \mathrm{H}_{2} \mathrm{O}
\end{aligned}
$$

Copper ions passing into the solution form copper amine complexes with ammonia. The formation reactions of the copper amine complexes can be written as follows:

$$
\begin{aligned}
& \mathrm{Cu}^{2+}+2 \mathrm{NH}_{3} \leftrightarrows \mathrm{Cu}\left(\mathrm{NH}_{3}\right)_{2}{ }^{2+} \\
& \mathrm{Cu}\left(\mathrm{NH}_{3}\right)_{2}{ }^{2+}+2 \mathrm{NH}_{3} \leftrightarrows \mathrm{Cu}\left(\mathrm{NH}_{3}\right)_{4}{ }^{2+}
\end{aligned}
$$

Thus, precipitation of copper does not occur during leaching. Because ammonium sulfate solutions have mildly acidic character, ferric ions $\left(\mathrm{Fe}^{3+}\right)$ passing into the solution during the leaching process precipitate in the form of $\mathrm{Fe}(\mathrm{OH})_{3}$. Thus, a high purity solution can be obtained.

In the second stage of the study, the cementation reaction between copper ions and zinc takes place according to the following reaction:
$\mathrm{Cu}^{2+}+\mathrm{Zn}^{\circ} \rightarrow \mathrm{Cu}^{\circ}+\mathrm{Zn}^{2+}$

Due to the difference between the electrode potentials of two metals, copper ions are easily reduced to the metallic state on the zinc surface, while zinc passes into the solution by dissolving.

In the final stage of this study, the cement copper obtained was converted to copper (II) oxide (CuO) by a thermal oxidation method. During the thermal oxidation process, $\mathrm{Cu}_{2} \mathrm{O}$ is first formed, and after a sufficiently long oxidation time, $\mathrm{CuO}$ is formed (Musa et al., 1998; Cocke et al., 2005; Korshunov, and Il'in, 2009). Thus, the reactions occurring during the thermal oxidation process can be written as follows:

$$
\begin{aligned}
& 2 \mathrm{Cu}_{(\mathrm{s})}+1 / 2 \mathrm{O}_{2(\mathrm{~g})} \rightarrow \mathrm{Cu}_{2} \mathrm{O}_{(\mathrm{s})} \\
& \mathrm{Cu}_{2} \mathrm{O}_{(\mathrm{s})}+1 / 2 \mathrm{O}_{2(\mathrm{~g})} \rightarrow 2 \mathrm{CuO}_{(\mathrm{s})}
\end{aligned}
$$

Copper oxide has many applications in areas like gas sensors, solar energy conversion cells, electronic cathode materials, semiconductors, and catalysts due to its electrical, optical, and catalytic properties (Darezereshki and Bakhtiari, 2011; Mema et al., 2011). Although various synthesis methods for preparing copper oxide are known, the thermal oxidation technique offers a simple, convenient, and fast method. Generally, high-purity copper foil has been used as a precursor to synthesize copper oxide by thermal treatment (Musa et al., 1998; Allam and Grimes, 2011). The material used in the present study for preparation of copper oxide can contribute to the process economy.

\section{MATERIALS AND METHODS}

\section{Material}

The malachite ore sample used in this study was supplied from the mine in Ovacik, Tunceli, Turkey. The ore sample was crushed, ground, and then sieved using standard test sieves to obtain the desired particle size fractions. The mineralogical analysis of the ore sample was performed using a Rigaku RadBDMAX II model X-ray diffractometer. The result of X-ray analysis given in Figure 1 indicates that the sample contains mainly malachite $\left(\mathrm{CuCO}_{3} \mathrm{Cu}(\mathrm{OH})_{2}\right)$, quartz $\left(\mathrm{SiO}_{2}\right)$, and smithsonite $\left(\mathrm{ZnCO}_{3}\right)$. The chemical analysis result of the sample is given in Table 1 . 


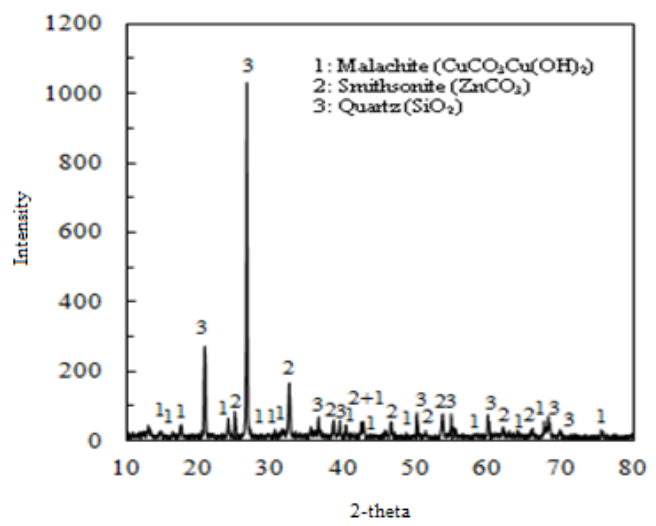

Figure 1: X-ray diffraction pattern for the malachite ore used in the study.

Table 1: Chemical analysis of the malachite ore used in this study.

\begin{tabular}{|c|c|c|c|c|c|c|c|}
\hline Component & $\mathbf{S i O}_{2}$ & $\mathbf{Z n O}$ & $\mathbf{C u O}$ & $\mathbf{F e}_{2} \mathbf{O}_{3}$ & $\mathbf{A l}_{2} \mathbf{O}_{3}$ & Ignition loss & $\begin{array}{c}\text { Other oxides } \\
(\mathbf{N a}, \mathbf{C a}, \mathbf{K}, \mathbf{M g}, \text { oxides })\end{array}$ \\
\hline Value $/ \%$ & 50.41 & 15.23 & 10.55 & 8.43 & 1.81 & 12.40 & 1.17 \\
\hline
\end{tabular}

\section{Method}

The leaching experiments were performed in a $1 \mathrm{~L}$ glass reactor equipped with a mechanical stirrer, a reaction temperature control unit, and a back-cooler. After putting $500 \mathrm{~mL}$ of an ammonium sulfate solution into the glass reactor and bringing it to operating reaction temperature, a given amount of ore sample was added to the solution, and the stirring speed was set. Aliquots of $5 \mathrm{~mL}$ of sample were taken at regular intervals during leaching, and were filtered. The amount of dissolved copper in the solution was determined complexometrically using Titriplex III solution as titrant and murexide as indicator. The copper amount passing into the solution was calculated as follows:

$\mathrm{x}=$ mass of copper passing to the solution/mass of copper in the ore sample.

To examine the attainability of metallic copper directly from the actual leach solution, an experiment was carried out via the metal displacement reaction (cementation) between copper ions in the solution and metallic zinc. The experimental setup in the cementation test was identical to the leaching process. The cementation experiment was carried out as in our previous studies (Demirkıran et al., 2007; Demirkıran and Künkül, 2011). After placing $500 \mathrm{~mL}$ of the leach solution containing $1 \mathrm{~g} / \mathrm{L}$ of copper ions into the glass reactor and bringing it to $50{ }^{\circ} \mathrm{C}$, zinc particles were added to the reactor, and the reactor content was stirred at $500 \mathrm{rpm}$ for $60 \mathrm{~min}$. During the experiment, the $\mathrm{pH}$ of the reaction solution was 3 . At the end of the cementation reaction, it was determined by the complexometric method that almost all of the copper in the leach solution had precipitated. After the metal precipitate accumulated at the bottom of the reactor, it was separated by filtration from the solution, washed with distilled water and ethyl alcohol, and then dried at $50{ }^{\circ} \mathrm{C}$ in air.

Copper obtained in the cementation step was used to prepare copper oxide by a thermal oxidation method. The thermal oxidation procedure was performed at atmospheric pressure under isothermal conditions in a muffle furnace at $500{ }^{\circ} \mathrm{C}$ for $5 \mathrm{~h}$. After placing $0.2 \mathrm{~g}$ of the cement copper in a ceramic crucible, the sample was placed inside the furnace. Following the oxidation process, the oxidized sample was cooled to room temperature.

The mineralogical analyses of the cement copper and copper oxide powders prepared were carried out using a Rigaku RadB-DMAX II model X-ray diffractometer. The morphological analysis of copper oxide was performed using a LEO-EVO 40 XVP model scanning electron microscope.

\section{RESULTS AND DISCUSSION}

While examining the leaching kinetics of different ores in various lixiviants, variables such as reaction temperature, solution concentration, solid to liquid ratio, particle size, and agitation speed are generally chosen as experimental parameters. The leaching data obtained are plotted as a function of conversion 
fraction versus reaction time, and the kinetic analysis is performed by using heterogeneous reaction models. In the leaching studies, the reaction rate generally increases with an increase in lixiviant concentration and with a decrease in solid to liquid ratio. From the standpoint of determining the rate-controlling step, reaction temperature, particle size, and agitation speed are often more important parameters. Thus, the effects of reaction temperature, particle size, and stirring speed on copper leaching from malachite ore were investigated. Before studying the effects of the above mentioned parameters, some experiments were performed to test the effects of ammonium sulfate concentration and solid to liquid ratio on the leaching rate, and the optimal values of these two parameters were determined to be $4 \mathrm{~mol} / \mathrm{L}$ and $2 \mathrm{~g}$ solid $/ 500 \mathrm{~mL}$ solution, respectively. The effects of other parameters, including agitation speed, particle size and reaction temperature, on the copper leaching from malachite ore were investigated by using these optimal values of ammonium sulfate concentration and solid to liquid ratio.

\section{Effect of Stirring Speed}

Experiments relating to the effect of stirring speed on the rate of copper leaching were carried out in the range from 200 to $600 \mathrm{rpm}$. In these tests, the ammonium sulfate concentration, solid to liquid ratio, particle size, and reaction temperature were kept constant at $4 \mathrm{~mol} / \mathrm{L}, 2 \mathrm{~g}$ ore $/ 500 \mathrm{~mL}$ solution, $62.4 \mu \mathrm{m}$, and $40^{\circ} \mathrm{C}$, respectively. Figure 2 illustrates the effect of the agitation speed on the leaching rate. The results showed that the dissolution rate increased considerably when the stirring speed increased from 200 to $500 \mathrm{rpm}$, and it did not change much after 500 $\mathrm{rpm}$. After 150 minutes of leaching time, it was found that the extent of leaching of copper increased from $64 \%$ to $83 \%$ when the stirring speed rose from 200 to $500 \mathrm{rpm}$. At a stirring speed of $600 \mathrm{rpm}, 85 \%$ of the copper was dissolved after the same leaching time. It was observed during experiments that the ore particles were fully suspended at $400 \mathrm{rpm}$ in the leach solution. Therefore, all subsequent experiments were conducted at an agitation speed of $400 \mathrm{rpm}$.

Because the agitation reduces the liquid film thickness formed around the ore particles, the diffusion through the boundary layer of the leach reagent toward the external surface of the particles eases. Hence, the dissolution rate increases with an increase in stirring speed. The results obtained for the effect of stirring speed indicate that this leaching process may be diffusion controlled. However, it does not imply that the rate of process is definitely controlled by dif- fusion through the fluid film. If the porous product layer is formed on the ore particle surface, the agitation can enhance the dissolution rate by increasing the internal diffusion toward the unreacted core surface. In such a case, the rate of the process may be controlled by diffusion through the product layer.

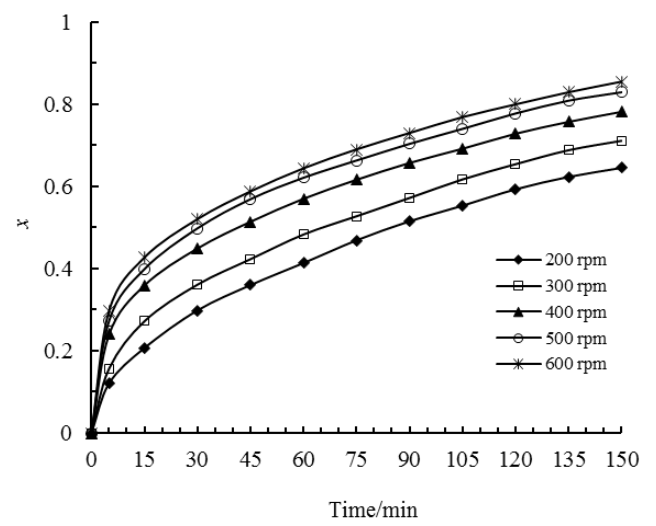

Figure 2: Effect of stirring speed on leaching of malachite ore.

\section{Effect of Particle Size}

In the determination of the rate-controlling step of a leaching process, the particle size of the ore is one of the most important parameters. Since the contact surface area enlarges upon reducing particle size, the leaching rate generally increases. To examine the effect of the particle size on copper extraction from the malachite ore, experiments were conducted by using fractions of the ore with average particle size of $136,120,93,71.5$, and $62.4 \mu \mathrm{m}$ while the values of ammonium sulfate concentration, solid to liquid ratio, stirring speed, and reaction temperature were kept constant at $4 \mathrm{~mol} / \mathrm{L}, 2 \mathrm{~g}$ solid $/ 500 \mathrm{~mL}$ solution, $400 \mathrm{rpm}$, and $40{ }^{\circ} \mathrm{C}$, respectively. Figure 3 represents the variations of the leaching rate for various particle sizes.

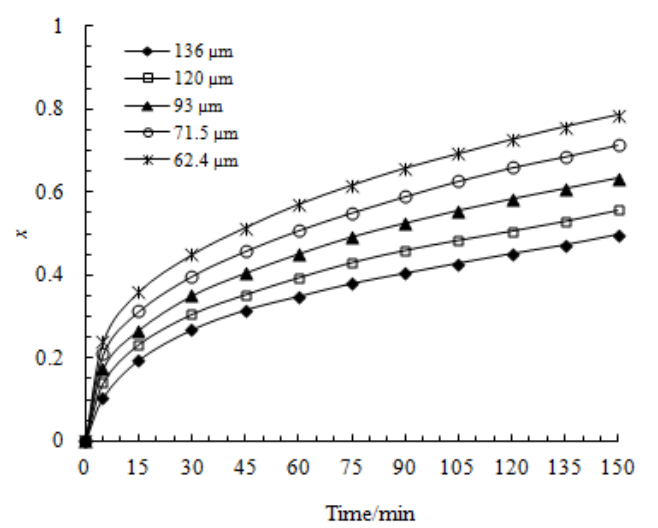

Figure 3: Effect of particle size on leaching of malachite ore. 
After 150 min of leaching, it was determined that the extent of extraction of copper from the malachite ore increased from $50 \%$ to $79 \%$ when the particle size was reduced from 136 to $62.4 \mu \mathrm{m}$. The results obtained for this experimental parameter show that the particle size has a considerable effect on the leaching of malachite ore in ammonium sulfate solutions. This result can be attributed to the increase of the particle contact surface with the decrease of the particle size per amount of solid.

\section{Effect of Reaction Temperature}

In the leaching studies, the reaction temperature often has an enhancing effect on the reaction rate due to the exponential dependence between the rate constant and temperature in the Arrhenius equation. The activation energy value calculated depending on temperature from the Arrhenius equation may give an idea about the rate-controlling step of a leaching process. Thus, the determination of the effect of reaction temperature on the leaching is an important issue.

The effect of reaction temperature on the leaching rate of copper from the malachite ore in ammonium sulfate solutions was examined at temperatures of $30,40,50,60$, and $70{ }^{\circ} \mathrm{C}$. While conducting these experiments, the values of ammonium sulfate concentration, solid to liquid ratio, particle size, and stirring speed were fixed at $4 \mathrm{~mol} / \mathrm{L}, 2 \mathrm{~g}$ solid $/ 500 \mathrm{~mL}$ solution, $62.4 \mu \mathrm{m}$, and $400 \mathrm{rpm}$, respectively. The experimental results determined for the effect of the reaction temperature on the leaching rate are given in Figure 4. It is seen that the leaching rate enhances with increasing reaction temperature. After $150 \mathrm{~min}$ of leaching, it was found that the extent of leaching of copper from the malachite ore increased from $68 \%$ to $98 \%$ when the reaction temperature increased from 30 to $70{ }^{\circ} \mathrm{C}$.

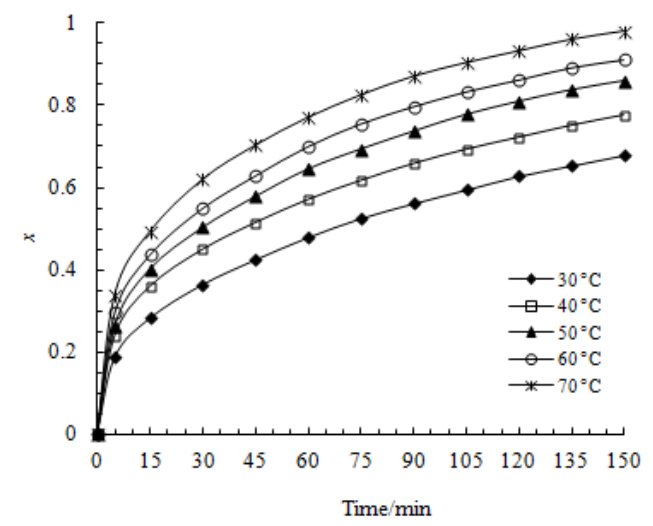

Figure 4: Effect of reaction temperature on leaching of malachite ore.
The rate constant of a chemical reaction depends on reaction temperature by means of the Arrhenius equation. In consequence of the exponential dependence between the rate constant and temperature in this equation, this is an expected situation that the reaction rate increases with increasing temperature.

\section{Kinetic Analysis}

The reaction occurring between malachite ore particles and ammonium sulfate solution during the leaching process is a typical example of heterogeneous liquid-solid reactions. These types of reactions are generally non-catalytic, and the kinetic analyses of them are done according to the non-catalytic heterogeneous reaction models. Among the non-catalytic heterogeneous reaction models, the most common model applied to leaching reactions is the shrinking core model. This model assumes that the reaction between solid and liquid reactants occurs on the outer surface of the solid particle. It is considered that the reacting particles are spherical, and their size does not change during reaction. As the reaction proceeds, the unreacted core of the solid particles shrinks toward the center of the solid, and a porous product layer may form around the unreacted core. The rate of the leaching reaction may be controlled by one or more of the following steps: the diffusion through a fluid film, the diffusion through the product layer, or the chemical reaction at the surface of the unreacted core. The integrated rate equations derived for each step above from the shrinking core model have been described in detailed in the literature (Wen, 1968; Levenspiel, 1972; Mazet, 1992), and they have been applied to many leaching processes.

To determine the kinetic parameters and the rate controlling-step of the dissolution of malachite ore in ammonium sulfate solutions, the data provided by the leaching tests were analyzed based on the shrinking core model using the integrated rate equations introduced by Levenspiel (1972). When the kinetic equations for diffusion through the fluid film and the chemical reaction models were applied to the experimental data, it was observed that parabolic curves were obtained for both models. Therefore, it can be said that these steps are not rate-controlling steps for the leaching process in this work. Among the kinetic models applied to leaching data, it was determined that the following model (the diffusion through the product layer) was more appropriate for the kinetics of the leaching of copper from malachite ore in ammonium sulfate solutions.

$$
1-3(1-x)^{2 / 3}+2(1-x)=\frac{6 b D_{e} C_{A}}{\rho_{B} R_{0}^{2}} t=k t
$$


By using the expression in Eq. (7), the apparent rate constants, $k$, were determined for each parameter. To determine the apparent rate constants, the left side of Eq. (7) was plotted versus the reaction time for each experimental parameter. The slopes of the straight lines obtained were considered to be the rate constants. Table 2 shows the apparent rate constant values and their correlation coefficients calculated by applying Eq. (7). The graphs constructed for the stirring speed, particle size and reaction temperature by using Eq. (7) are given in Figures 5-7, respectively. The linear relation between $1-3(1-x)^{2 / 3}+2(1-x)$ and reaction time can be seen for the above-mentioned parameters from these figures. In accordance with the results shown in Table 2 and in Figures 5-7, it can be concluded that the model in Eq. (7) is suitable to represent the leaching kinetics of this process. Therefore, the rate expression for this leaching process can be written as follows:

$$
1-3(1-x)^{2 / 3}+2(1-x)=k t
$$

Table 2: The apparent rate constants, $k$, for the kinetic model and correlation coefficient values.

\begin{tabular}{|c|c|c|}
\hline Parameter & $\begin{array}{c}\text { Diffusion through the product layer } \\
\mathbf{1 - 3}(\mathbf{1}-\boldsymbol{x})^{\mathbf{2} \mathbf{3}}+\mathbf{2}(\mathbf{1}-\boldsymbol{x})\end{array}$ \\
\hline & $\left.\boldsymbol{k} \mathbf{( m i n}^{\mathbf{- 1}}\right)$ & $\boldsymbol{R}^{\mathbf{2}}$ \\
\hline Temperature/ ${ }^{\mathbf{0}} \mathbf{C}$ & 0.0016 & 0.998 \\
30 & 0.0024 & 0.995 \\
50 & 0.0032 & 0.996 \\
60 & 0.0041 & 0.997 \\
70 & 0.0053 & 0.995 \\
\hline Stirring speed/rpm & \multicolumn{2}{|}{} \\
\hline 200 & 0.0013 & 0.994 \\
300 & 0.0018 & 0.998 \\
400 & 0.0024 & 0.995 \\
500 & 0.0029 & 0.990 \\
600 & 0.0032 & 0.990 \\
\hline Particle size/ $\boldsymbol{\mu m}$ & 0.0007 & 0.992 \\
136 & 0.0010 & 0.990 \\
93.0 & 0.0013 & 0.994 \\
71.5 & 0.0018 & 0.996 \\
62.4 & 0.0024 & 0.995 \\
\hline
\end{tabular}

To establish the effects of the reaction parameters on the apparent rate constant, the following equation may be suggested:

$$
k=k_{0}(P S)^{a}(S S)^{b} \exp \left(-E_{a} / R T\right)
$$

Combining Eqs. (8) and (9), the following kinetic expression including the parameters can be written:

$$
\begin{aligned}
& 1-3(1-x)^{2 / 3}+2(1-x) \\
& =k_{0}(P S)^{a}(S S)^{b} \exp \left(-E_{a} / R T\right) t
\end{aligned}
$$

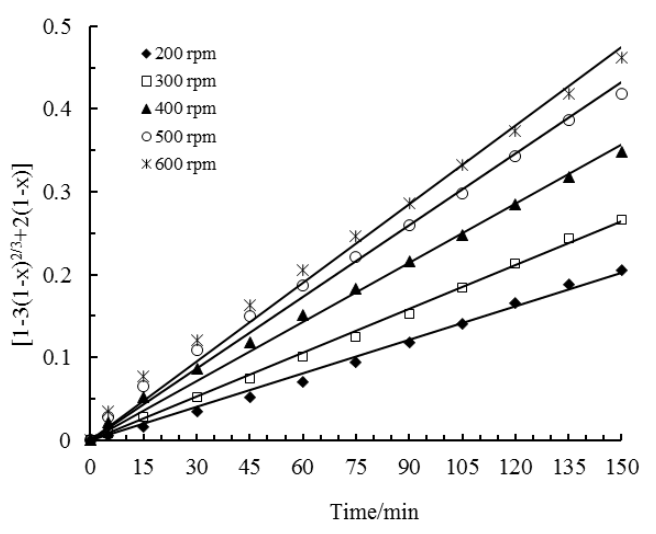

Figure 5: Plot of $\left[1-3(1-x)^{2 / 3}+2(1-x)\right]$ versus time for different stirring speeds.

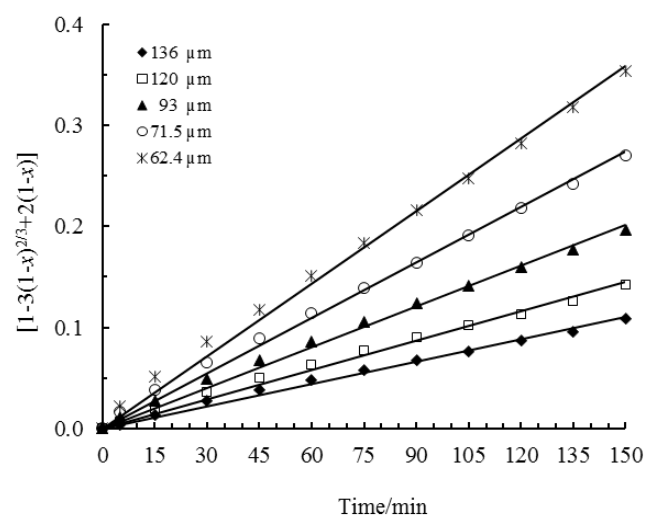

Figure 6: Plot of $\left[1-3(1-x)^{2 / 3}+2(1-x)\right]$ versus time for different particle sizes.

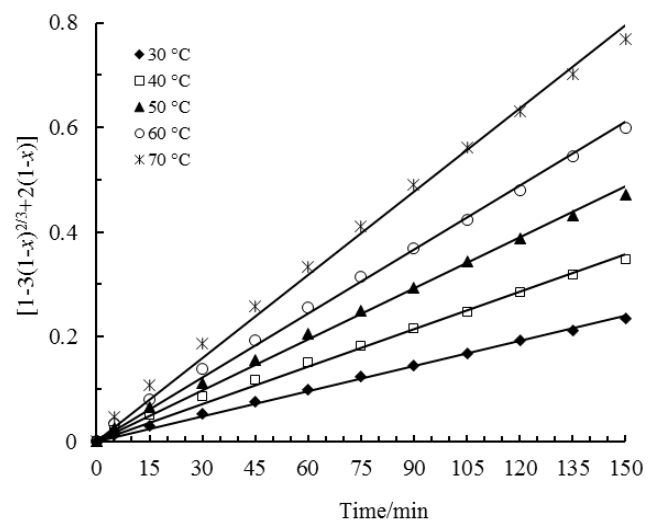

Figure 7: Plot of $\left[1-3(1-x)^{2 / 3}+2(1-x)\right]$ versus time for different reaction temperatures.

The constants $a$ and $b$ are the reaction order for the particle size and stirring speed, respectively. The values of these constants can be estimated by using the apparent rate constants given in Table 2. To determine these constants, the plots of $\ln (k)$ versus $\ln$ $(P S)$ and $\ln (k)$ versus $\ln (S S)$ were constructed by using the values given in Table 2 for the particle size 
and stirring speed, respectively. Figure 8 shows the plot of $\ln (k)$ versus $\ln (P S)$ for particle size. The slope of the straight line in this figure gives the reaction order with respect to particle size. The reaction order was proportional to the -1.44 power of particle size with a correlation coefficient of 0.982 . Similarly, the reaction order for stirring speed was found to be 0.85 with a correlation coefficient of 0.995 .

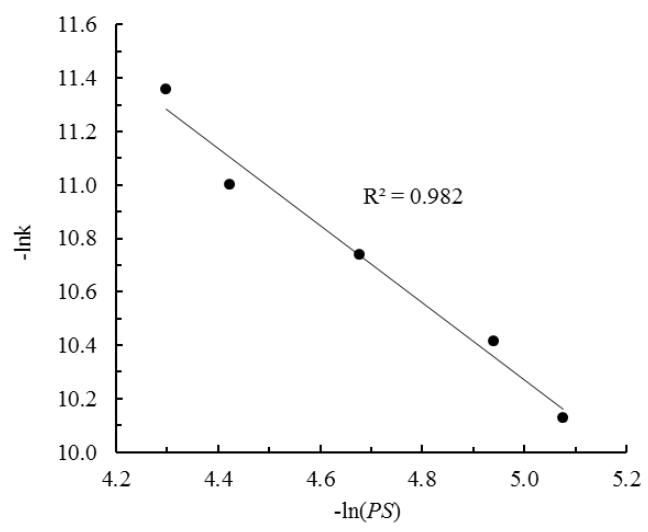

Figure 8: Plot of $\ln k$ versus $\ln (P S)$.

To calculate the activation energy of this process, an Arrhenius plot shown in Figure 9 was constructed.

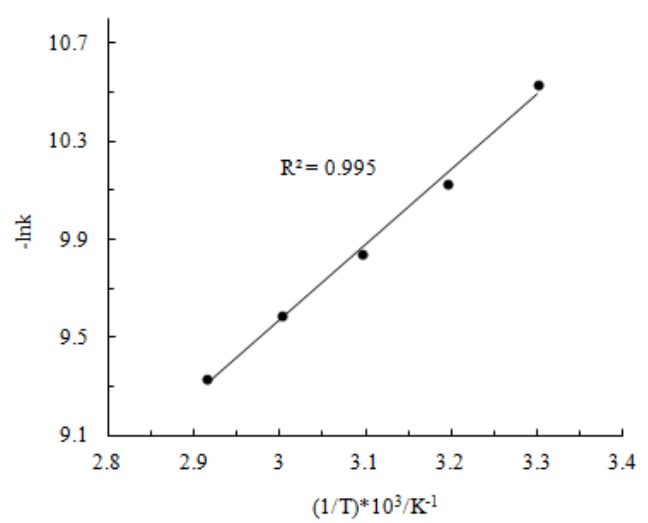

Figure 9: Arrhenius plot for the leaching process.

The activation energy and the intercept were estimated to be $25.4 \mathrm{~kJ} / \mathrm{mol}$, and 0.66 , respectively. The value of the activation energy of a leaching process may be used to prognosticate about the rate-controlling step of reaction. In the literature, it is expressed that diffusion controlled processes are slightly dependent on the reaction temperature, while chemical reaction controlled processes are strongly dependent on the reaction temperature. The activation energy of a diffusion controlled process is generally below $40 \mathrm{~kJ} / \mathrm{mol}$, while for a chemically controlled process this value is usually greater than $40 \mathrm{~kJ} / \mathrm{mol}$ (Habashi,
1983; Ekmekyapar et al., 2012c). Accordingly, the value of the activation energy obtained in the present study supports that this leaching process is controlled by diffusion through the product layer. Consequently, a mathematical expression including the experimental parameters to represent the kinetics of this leaching process may be written as follows:

$$
\begin{aligned}
& 1-3(1-x)^{2 / 3}+2(1-x) \\
& =0.66(P S)^{-1.44}(S S)^{0.85} \exp (-25400 / R T) t
\end{aligned}
$$

\section{Recovery of Copper from Leach Solution}

After leaching of the malachite ore, copper passing into the leach solution was recovered in the form of metal by the cementation reaction with metallic zinc.

The metallic copper produced by the cementation process cannot be obtained at high-purity due to the impurities in the leaching solution and its tendency to oxidize. It was determined that the red-brown copper powder produced by the metal displacement reaction contained $90 \% \mathrm{Cu}$. The copper content of the metallic product obtained by cementation was increased up to $96 \%$ after it was treated with dilute hydrochloric acid. Figure 10 shows the XRD pattern of the copper powder obtained after acid treatment. As can be seen in Figure 10, the major diffraction peaks correspond to copper, while the minor peaks indicate the cuprous oxide $\left(\mathrm{Cu}_{2} \mathrm{O}\right)$ phase. Cuprous oxide likely is formed by oxidation during drying the wet cement copper. Even if cement copper is not very high-purity, it can be evaluated as powder, or other copper compounds can be produced from it.

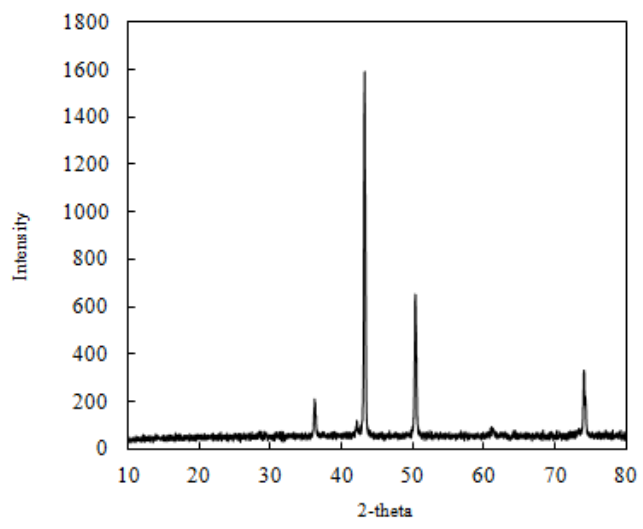

Figure 10: X-ray diffraction pattern of cement copper obtained from the leach solution.

Figure 11 shows the XRD pattern of the oxidized product obtained after heat treatment at $500^{\circ} \mathrm{C}$ for $5 \mathrm{~h}$. 
All of the diffraction peaks observed in this figure indicate that the oxide product prepared is $\mathrm{CuO}$, which has the monoclinic tenorite structure. Form the SEM image shown in Figure 12, it is observed that the oxide product particles are in a highly agglomerated state.

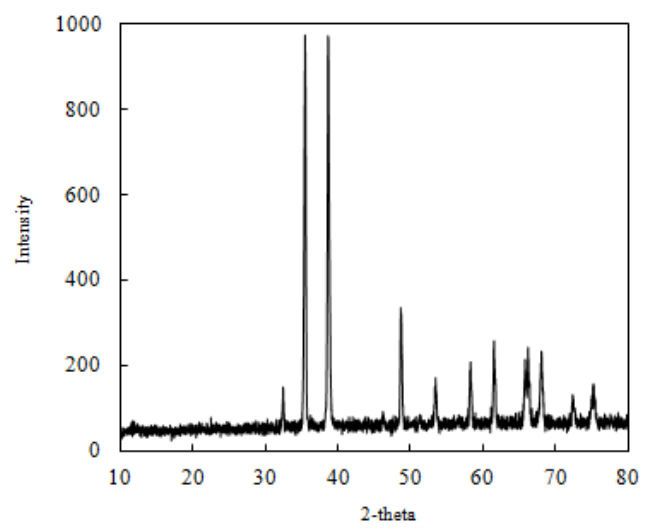

Figure 11: X-ray diffraction pattern of copper oxide obtained by thermal oxidation of cement copper.

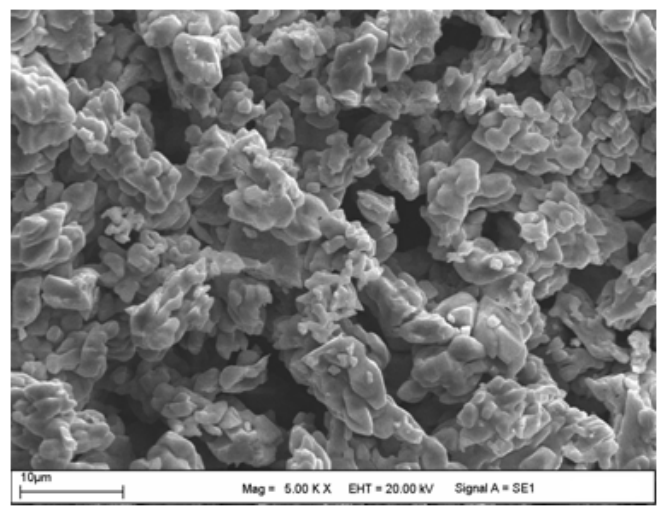

Figure 12: SEM image of copper oxide obtained by thermal oxidation of cement copper.

From the experimental observations and findings obtained in this study, it can be concluded that the various copper products can be readily produced by using the resulting solutions after leaching of the malachite ore in ammonium sulfate solutions.

At the end of the leaching and cementation processes, the resulting waste solution contains considerably high amount of zinc ions. Therefore, recovering of zinc ions from this solution can be important both environmentally and economically. Zinc ions can be recovered from such a solution by various methods, like electrolysis and chemical precipitation (Demirkıran, 2013c). Hence, zinc can be recovered in addition to copper from malachite ore. This will be examined in our next studies.

\section{CONCLUSIONS}

The leaching kinetics of malachite in ammonium sulfate solutions and the recoverability of copper from the resulting actual leach solution were examined in the present study. The producibility of copper oxide from cement copper was also studied.

In the leaching step of the study, the effects of reaction temperature, particle size, and stirring speed on copper leaching from malachite ore were investigated. Maximum copper extraction (98\%) from malachite ore was achieved at experimental conditions of $4 \mathrm{~mol} / \mathrm{L}, 2 / 500 \mathrm{~g} / \mathrm{mL}, 400 \mathrm{rpm}, 62.4 \mu \mathrm{m}, 70{ }^{\circ} \mathrm{C}$, and $150 \mathrm{~min}$. It was determined that the leaching rate increased with increasing stirring speed and reaction temperature, and decreased with particle size. It was observed that the leaching reaction fit to the diffusion through the product layer model. The activation energy of the leaching process was determined to be $25.4 \mathrm{~kJ} / \mathrm{mol}$. In the second step of this study, copper in the resulting solution after leaching step was recovered by the cementation method using zinc metal as the reducing agent. It was found that the copper in the solution was completely precipitated. It was determined that the metallic product obtained by the cementation method contained $90 \% \mathrm{Cu}$, and it could be increased up to $96 \%$. This copper product was used as raw material to prepare copper oxide by isothermal oxidation in the third step of the study. Thermal treatment was performed at atmospheric pressure at $500{ }^{\circ} \mathrm{C}$ for $5 \mathrm{~h}$. At the end of this operation, it was observed that copper oxide prepared from cement copper had a tenorite structure. The copper oxide obtained can be used as raw material to produce various copper compounds.

In addition, because the resulting waste solution at the end of cementation process contains considerably high amounts of zinc ions, this solution can be evaluated to recover the zinc by various methods. Hence, zinc can be also recovered in addition to copper from malachite ore. Because the process practiced in this study does not require expensive and specialized equipment, it can be applied in an economic way for the production of copper or copper compounds after hydrometallurgical processing of lowgrade malachite ore. As a result, directly sellable copper products (metallic copper and copper oxide) were produced from malachite ore at the end of these three steps.

\section{REFERENCES}

Agarwal, S., Ferreira, A. F., Santos, S. M. C., Reis, M. T. A., Ismael, M. R. C., Carreia, M. J. N., Carvalho, 
J. M. R., Separation and recovery of copper zinc leach liquor by solvent extraction using Acorga M5640. Int. J. Miner. Process., 97, 85-91 (2010).

Ahmed, I. M., El-Nadi, Y. A., Daoud, J. A., Cementation of copper from spent copper-pickle sulfate solution by zinc ash. Hydrometallurgy, 110, 62-66 (2011).

Allam, N. K., Grimes, C. A., Electrochemical fabrication of complex copper oxide nanoarchitectures via copper anodization in aqueous and non-aqueous electrolytes. Mater. Lett., 65, 1949-1955 (2011).

Arzutuğ, M. E., Kocakerim, M. M., Çopur, M., Leaching of malachite ore in $\mathrm{NH}_{3}$-saturated water. Ind. Eng. Chem. Res., 43, 4118-4123 (2004).

Awakura, Y., Hirato, T., Kagawa, A., Yamada Y., Majima, H., Dissolution of malachite in aqueous ethylenediaminetetraacetate solution. Metall. Trans. B., 22B, 569-574 (1991).

Bingöl, D., Canbazoğlu, M., Aydoğan, S., Dissolution kinetics of malachite in ammonia/ammonium carbonate leaching. Hydrometallurgy, 76, 55-62 (2005).

Blanco, L. J. L., Zapata, V. F. M., Garcia, D. D. J., Statistical analysis of laboratory results of $\mathrm{Zn}$ wastes leaching. Hydrometallurgy, 54, 41-48 (1999).

Cocke, D. L., Schennach, R., Hossain, M. A., Mencer, D. E., McWhinney, H., Parga, J. R., Kesmez, M., Gomes, J. A. G., Mollah, M. Y. A., The low-temperature thermal oxidation of copper, $\mathrm{Cu}_{3} \mathrm{O}_{2}$, and its influence on past and future studies. Vacuum, 79, 71-83 (2005).

Darezereshki, E., Bakhtiari, F., A novel technique to synthesis of tenorite $(\mathrm{CuO})$ nanoparticles from low concentration CuSO4 solution. J. Min. Metall. Sect. B-Metall., 47, 73-78 (2011).

Deep, A., Kumar, P., Carvalho, J. M. R., Recovery of copper from zinc leaching liquor using ACORGA M5640. Sep. Purif. Technol., 76, 21-25 (2010).

Demirkıran, N., Ekmekyapar, A., Künkül, A., Baysar, A., A kinetic study of copper cementation with zinc in aqueous solutions. Int. J. Miner. Process., 82, 80-85 (2007).

Demirkıran, N., Künkül, A., Recovering of copper with metallic aluminum. T. Nonferr. Met. Soc. China, 21, 2778-2782 (2011).

Demirkıran, N., A study on preparation of copper powder without an external electrical current source. Revista de Chimie, 64, 378-381 (2013a).

Demirkıran, N., Copper cementation with zinc recovered from zinc-carbon batteries and dissolution of cement copper in hydrochloric acid solutions. Ind. Eng. Chem. Res., 52, 8157-8166 (2013b).
Demirkıran, N., Recovery of zinc ions from the resulting solution after copper cementation with metallic zinc. Sep. Sci. Technol., 48, 827-832 (2013c).

Dib, A., Makhloufi, L., Cementation treatment of copper in wastewater: mass transfer in a fixed bed of iron spheres. Chem. Eng. Process., 43, 12651273 (2004).

Djokic, S. S., Cementation of copper on aluminum in alkaline solutions. J. Electrochem. Soc., 143, 13001305 (1996).

Ekmekyapar, A., Oya, R., Künkül, A., Dissolution kinetics of an oxidized copper ore in ammonium chloride solution. Chem. Biochem. Eng. Q., 17, 261-266 (2003).

Ekmekyapar, A., Aktaş, E., Künkül, A., Demirkıran, N., Investigation of leaching kinetics of copper from malachite ore in ammonium nitrate solutions. Metall. Mater. Trans. B., 43B, 764-772 (2012a).

Ekmekyapar, A., Tanaydın, M., Demirkıran, N., Investigation of copper cementation kinetics by rotating aluminum disc from the leach solutions containing copper ions. Phsicochem. Probl. Miner. Process., 48, 355-367 (2012b).

Ekmekyapar, A., Asin, C., Demirkıran, N., Künkül, A., Baysar, A., Ceylan, K., Reductive leaching of pyrolusite ore by using sawdust for production of manganese sulfate. Russ. J. Non-Ferr. Met., 53, 211-217 (2012c).

Figueroa, M., Gana, R., Kattan, L., Mendez, S., Palma, L., Anode-support system for the direct electrorefining of cement copper. Part III: Pretreatment and process conditions to refine industrial cement. J. Appl. Electrochem., 27, 99-103 (1997).

Fouad, E. A., Separation of copper from aqueous sulfate solutions by mixtures of Cyanex301 and LIX984N. J. Hazard. Mater., 166, $720-727$ (2009).

Gana, R., Figueroa, M., Sanchez, J. M., Esteso, M. A., Anode-support system for the direct electrorefining of cement copper. Part I: Process conditions using horizontal rotary cathodes. J. Appl. Electrochem., 25, 240-246 (1995).

Ghosh, M. K., Das, R. P., Biswas, A. K., Oxidative ammonia leaching of spharelite Part I: Noncatalytic kinetics. Int. J. Miner. Process., 66, 241-254 (2002).

Gupta, C. K., Murkherjee, T. K., Hydrometallurgy in Extraction Processes. CRC Press, USA (1990).

Habashi, F., Dissolution of minerals and hydrometallurgical process. Naturwissenschaften, 70, 403411 (1983).

Habashi, F., Handbook of Extractive Metallurgy. Wiley, New York, (1997). 
Han, K. N., Fundamentals of Aqueous Metallurgy. SME Inc., USA (2002).

Hu, H. P., Liu, C. X., Han, X. T., Liang, Q. W., Chem, Q. Y., Solvent extraction of copper and ammonia from ammoniacal solutions using sterically hindered $\beta$-diketone. T. Nonferr. Met. Soc. China, 20, 2026-2031 (2010).

Karavasteva, M., Kinetics and deposit morphology of copper cementation onto zinc, iron and aluminum. Hydrometallurgy, 76, 149-152 (2005).

Künkül, A., Kocakerim, M. M., Yapıc1, S., Demirbağ, A., Leaching kinetics of malachite in ammonia solutions. Int. J. Miner. Process., 41, 167-182 (1994).

Künkül, A., Gülezgin, A., Demirkıran, N., Investigation of the use of ammonium acetate as an alternative lixiviant in the leaching of malachite ore. Chem. Ind. Chem. Eng. Q., 19, 25-35 (2013).

Korshunov, A. V., Il'in, A. P., Oxidation of copper nanopowders on heating in air. Russ. J. Appl. Chem., 82, 1164-1171 (2009).

Levenspiel, O., Chemical Reaction Engineering. John Wiley, New York (1972).

Liu, Z. X., Yin, Z. L., Hu, H. P., Chen, Q. Y., Leaching kinetics of low-grade copper ore with high-alkality gangues in ammonia-ammonium sulphate solution. J. Cent. South. Univ., 19, 77-84 (2012).

Lui, W., Tang, M. T., Tang, C. B., He, J., Yong, S. H., Yang, J. G., Dissolution kinetics of low grade complex copper ore in ammonia-ammonium chloride solution. T. Nonferr. Met. Soc. China, 20, 910917 (2010).

Mazet, N., Modeling of gas-solid reactions 1. Nonporous solids. Int. Chem. Eng., 32, 271-284 (1992).

Mema, R., Yuan, L., Du, Q., Wang, Y., Zhou, G., Effect of surface stresses on $\mathrm{CuO}$ nanowire growth in the thermal oxidation. Chem. Phys. Lett., 512, 87-91 (2011).

Musa, A. O., Akomolafe, T., Carter, M. J., Production of cuprous oxide, a solar cell material, by thermal oxidation and a study of its physical and electrical properties. Solar Energy Mater. Solar Cells, 51, 305-316 (1998).

Naguman, P. N., The chemistry and kinetics of oxidized copper sulfiding by sodium thiosulfate. Russ. J. Non-Fer. Met., 49, 433-437 (2008).

Noubactep, C., Elemental metals for environmental remediation: Learning from cementation process. J. Hazard. Mater., 181, 1170-1174 (2010).

Oudenne, P. D., Olson, F. A., Leaching kinetics of malachite in ammonium carbonate solutions. Metall. Trans. B., 14B, 33-40 (1983).

Salavati-Niasari, M., Davar, F., Synthesis of copper and copper (I) oxide nanoparticles by thermal decomposition of a new precursor. Mater. Lett., 63, 441-443 (2009).

Staszak, K., Rosocka, M. R., Wieszczycka, K., Burmistrzak, P., Copper (II) sulphate solutions treatment by solvent extraction with Na-Cyanex 272 . Sep. Purif. Technol., 85, 183-192 (2012).

Tsogtkhankhai, D., Mamyachenkov, S. V., Anisimova, O. S., Naboichenko, S. S., Thermodynamics of reactions during nitric acid leaching of minerals of a copper concentrate. Russ. J. Non-Fer. Met., 52, 135-139 (2011).

Wang, X., Chen, Q., Hu, H., Yin, Z., Xiao, Z., Solubility prediction of malachite in aqueous ammoniacal ammonium chloride solutions at $25{ }^{\circ} \mathrm{C}$. Hydrometallurgy, 99, 231-237 (2009).

Wen, C. Y., Noncatalytic heterogeneous solid-fluid reaction models. Ind. Eng. Chem., 60, 34-54 (1968).

Venkatachalam, S., Hydrometallurgy. Narosa Publishing House, India (1998). 